\title{
Acute sacral epidural abscess following local anaesthetic injection
}

\author{
M. H. A. RUSTIN* \\ B.Sc., M.R.C.P. \\ M. D. FLYNN $\dagger$ \\ M.R.C.P. \\ E. N. COOMES $\dagger$ \\ M.D., F.R.C.P. \\ ${ }^{*}$ Department of Dermatology, St Bartholomew's Hospital, West Smithfield, London EC1A $7 B E$ and $†$ St Stephen's \\ Hospital, Fulham Road, Chelsea, London SWI0 9TH
}

\begin{abstract}
Summary
Spinal epidural abscesses are uncommon infections of the central nervous system. Delay in making the diagnosis increases the morbidity and mortality because irreversible neurological damage occurs during this time. We report a 45-year-old male who developed an acute sacral epidural abscess following a local anaesthetic injection given for the relief of low back pain. We believe this is the first documented case of a local anaesthetic injection causing an acute sacral epidural abscess.
\end{abstract}

KEY WORDS: local anaesthetic, abscess, epidural space.

\section{Introduction}

The incidence of spinal epidural abscesses is 0.2-1.2 per 10,000 hospital admissions (Baker et al., 1975) and most neurosurgical departments treat at least one case a year. The cervical, thoracic and lumbar regions are most commonly involved (Hancock, 1973) and less than 5\% of reported cases affect the sacral canal. Most of the latter have been extensions of abscesses in other vertebrae and very few have been confined to the sacral canal. This report presents one such case in a man who had reduced immunity due to undiagnosed Type II diabetes mellitus and was given a local anaesthetic injection into the sacrococcygeal area.

\section{Case report}

A 45-year-old male lorry driver presented with a 4 week history of mild, non-radiating low back pain which was unaffected by coughing or sneezing. On examination, there was tenderness of the sacrum and coccyx but no neurological signs. The duty casualty officer injected approximately $5 \mathrm{ml}$ of $1 \%$ plain lignocaine from a sealed ampoule into the sacrococ- cygeal area producing pain relief. Four days later, the patient returned to casualty complaining of increasingly severe low back pain and was admitted for investigation. There was no history of back injury or recent skin sepsis. His father was an insulin-dependent diabetic.

On examination, he was apyrexial and there was obvious tenderness over the mid-sacrum. Twentyfour hours later, he became pyrexial at $37.6 \mathrm{C}$ and developed the signs of a midline cauda equina lesion; painless urinary retention, loss of sacral sensation (saddle anaesthesia), diminished anal tone and an absent bulbo-cavernosus reflex. There were no other neurological findings.

Investigations: Haemoglobin concentration 11.9 $\mathrm{g} / \mathrm{dl}$; while cell count $15.3 \times 10^{9} /$ litre with $89 \%$ neutrophils; erythrocyte sedimentation rate (ESR) 76 $\mathrm{mm} / \mathrm{hr}$; fasting blood glucose $10 \mathrm{mmol} /$ litre (normal range 3.3-5.6); serum thyroxine $30 \mathrm{nmol} /$ litre (normal range 45-160); TSH greater than 60 (normal range less than 10). X-rays of pelvis, lumbar and sacral spine were normal. A bone scan was normal. A myelogram showed attenuation and constriction of the subarachnoid space from L5 downwards. Cerebrospinal fluid (CSF) showed no cells, no organisms, protein $1.0 \mathrm{~g} /$ litre (normal $0 \cdot 1-0.5$ ) and glucose 6 $\mathrm{mmol} / \mathrm{litre}$.

A laminectomy of the posterior sacral arch and the fifth lumbar vertebra released pus under pressure from an extradural sacral canal abscess. The abscess was drained and culture grew Staphylococcus aureus. Parenteral flucloxacillin was given for one month postoperatively. The diabetes was controlled with oral hypoglycaemic agents and thyroxine replacement started. Six months later, perianal sensation is impaired, but bladder and sexual function are normal. 


\section{Discussion}

Acute epidural abscesses are associated with a characteristic clinical picture. There is a progression of unbearable unrelenting back pain, spinal root pain, impaired cord function with increasing neurological deficit and finally paralysis (Heusner, 1948). The terms extradural and epidural are synonymous. The average time interval between the onset of the pain and paralysis is 4-9 days (Hakin, Burt and Cook, 1979) and the neurological deficit is invariably complete within $48 \mathrm{hr}$ of its onset. There is usually a high fever, tachycardia, leucocytosis and an elevated ESR. CSF analysis shows an elevated protein, a cellular pleocytosis and a normal glucose provided there is no meningitis. Spinal radiography may or may not show vertebral osteomyelitis, but a myelogram is usually abnormal.

Infection of the epidural space arises by either direct extension of a contiguous infection or via the blood from a distant site of infection (Dandy, 1926). The most common organism isolated is Staphylococcus aureus but other causative organisms include Actinomyces israeli, streptococci, Escherichia coli, Pseudomonas aeruginosa, salmonella and anaerobes. In $85 \%$ of cases, a primary source of infection is found, usually skin sepsis. In our patient, the local anaesthetic injection probably introduced infection directly into the epidural space at the level of L5-S1. Alternatively, the needle could have entered the sacral canal via the sacral hiatus. Trotter (1947) in an extensive study, found wide anatomical variations in the size, shape and orientation of the sacral bone. The sacral hiatus may be almost closed or widely open depending on the pattern of fusion of the laminae of the sacral arches and sacral spina bifida occurs in about $2 \%$ of males and $0.3 \%$ females. Thus in some subjects, easy access can be gained to the sacral canal and its epidural space, thereby increasing the danger of random injections in this region.

The incidence of spinal epidural abscess following epidural anaesthesia is surprisingly low considering the number performed. This presumably reflects the strict aseptic technique followed during and after insertion of the catheter. Usubiaga (1975) collected reports of 13 cases, 7 following caudal and 6 after lumbar epidural anaesthesia. North and Brophy (1979) reported two cases, one caused by contamination of the local anaesthetic vial with Staphylococcus aureus and the other, in common with our patient, probably caused by introduction of Staphylococci during insertion of the needle. In 32 patierts having uncomplicated epidural anaesthesia, Barreto (1962市 showed growth of bacteria from 3 indwelling cathet ers at the moment of withdrawal from the epidura space. Moreover, despite strict aseptic techniquesis culture of skin swabs were positive in $30 \%$ of these patients.

The cause of the 4 week history of low back pain is not certain. We suspected a musculoskeletal caus 8 related to long distance driving and minor degenera tive disc disease was evident. We do not think tha? the pain was caused by a chronic epidural absces $\vec{\odot}$ since there was no evidence of osteomyelitis on bone scan or histology and no granulation tissue was foun at operation. The hypothyroidism may have delaye and diminished the pyrexia.

Definitive treatment is an urgent decompressiver laminectomy and appropriate antibiotics. The excel: lent outcome in this patient is a result of the earlye diagnosis and surgical drainage. Surprisingly, there is little evidence the diagnosis is made any earlier todase than in the pre-antibiotic era. Local anaesthetio injections given either by themselves or in combination with corticosteroids are commonly used in the treatment of rheumatic disorders (Bourne, 1979). We्ల wish to emphasise the importance of meticulous. asepsis when injecting near the spinal canal $2 \infty_{\infty}$ prevent introduction of infection and the risk further epidural abscesses.

\section{References}

Baker, A.S.. OJemann, R.G., Swartz, M.N. \& Richardson, E.P弘 (1975) Spinal epidural abscess. New England Journal of Medicine 293, 463.

BARRETO, R.S. (1962) Bacteriological culture of indwelling epidura catheters. Anaesthesiologv. 23, 643

BOURNE. I.H.J. (1979) Treatment of backache with local injectionsठ The Practitioner, 222, 708.

DANDY. W.E. (1926) Abscesses and inflammatory tumors in the spinal epidural space (so-called pachymeningitis externa) Archives of Surgery, 13, 477.

HAKIN, R.N.. BURT. A.A. \& COOK, J.B. (1979) Acute spinal epidurab abscess. Paraplegia, 17, 330.

HANCOCK, D.O. (1973) A study of 49 patients with acute spinab epidural abscess. Paraplegia, 10, 285

HEUSNER. A.P. (1948) Nontuberculous spinal epidural infections New England Journal of Medicine, 239, 845

NORTH, J.B. \& BROPHY. B.P. (1979) Epidural abscess: a hazard of spinal epidural anaesthesia. Australia and New Zealand Journal oم Surgery, 49. 484.

TROTTER, M. (1947) Variations of the sacral canal: their significances in the administration of caudal analgesia. Anesthesia Analgesia 26. 192.

Usubiacia. J.E. (1975) Neurological complications following epidural anesthesia. International anesthesiology clinics, 13, 54. 